\title{
Comentarios a la influencia de la obra de Vygotski en la psicología del lenguaje *
}

\section{Miguel Siguán}

Universidad de Barcelona

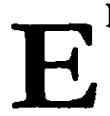

N 1930 se celebró en Barcelona la VI Conferencia Internacional de Psicotecnia y entre los inscritos figuraba el ruso Lev Vygotski. Por aquel entonces, todos los psicotécnicos del mundo no llegaba al centenar y en Barcelona se reunieron casi la mitad, pero Vygotski, crónicamente enfermo, no estaba entre ellos, sino que se limitó a enviar una comunicación titulada "El problema de las funciones psíquicas superiores", que figura en el volumen de actas del congreso, pero que hasta ahora que yo sepa no ha sido tenida en cuenta por sus biógrafos y que espero publicar próximamente. Aunque la verdad es que a pesar de que el volumen de actas de tal congreso ha estado entre mis libros casi desde mi adolescencia y más de una vez lo habia ojeado, el nombre del psicólogo ruso no me decía gran cosa.

Como tanta gente, descubri a Vygotski en la traducción inglesa de "Pensamiento y lenguaje», publicada por el MIT en 1962, y que llegó a mis manos en la reimpresión de 1969 . Por aquel entonces yo empezaba a ocuparme a fondo del lenguaje, me había dado cuenta de las limitaciones de Piaget en este campo y estaba intentando situarme frente a la marea chomskiana en plena ascensión. $Y$ conste que en el estudio del lenguaje infantil la tal marea fue extraordinariamente útil renovando a la vez los problemas y los métodos. Pero en el terreno de las explicaciones y desde una perspectiva psicológica, la postura de Chomsky me parecía estéril a la vez que absurda. Me parecía de mero sentido común que la aparición del lenguaje en el niño sólo podía explicarse desde su sociabilidad inicial, desde los procesos de comunicación que sostiene con los que le rodean, desde los primeros días de su vida. La lectura del libro de Vygotski me dio los ánimos necesarios para sostener esta tesis en el simposio de 197 s en Barcelona de la Association dePsychologie de Langue Française dedicado a la génesis

* Con el número cerrado y en parte impreso, que nos obliga a incluirla en el pliego final, nos llega esta aportación urgente de Miguel Siguán, a quien queremos agradecer el sumarse, apenas sin tiempo, a este número homenaje a Vygotski. 
del lenguaje en una ponencia titulada «De la comunicación gestual al lenguaje verbal». Otros autores con más experiencia y prestigio que yo habían llegado a parecidas conclusiones - Bruner publicó en aquel mismo año «From communication to language: a psychological perspectiven. Cognition, 1975, 3- y lo que en aquel momento parecía una gran novedad, el buscar la génesis del lenguaje verbal en las primeras formas de comunicación infantil, hoy se ha convertido en un lugar común. En todo caso, desde entonces me considero más o menos vigotskiano.

No voy a intentar resumir aquí las ideas de Vygotski sobre el lenguaje. Sólo querria destacar lo que a mi juicio constituye el núcleo central de su pensamiento y que es, o al menos así lo entiendo, el intentar explicar el desarrollo humano con una explicación que tenga en cuenta a la vez su base fisiológica y su inserción social no como una mera superposición de dos realidades y de dos explicaciones, sino como una síntesis de la que surge la naturaleza del hombre consciente e intencional. Es la misma preocupación que movía a Wallon, aunque para Wallon el punto de engarce entre fisiología y sociedad era la emoción, un trastorno físiológico convertido en expresivo por la respuesta de los demás, y para Vygotski es el gesto vocal convertido en palabra significativa en la comunicación.

Si renuncio a extenderme sobre las ideas de Vygotski en torno al lenguaje no renuncio, en cambio, a hacer algunas consideraciones generales en relación con ellas.

La primera se refiere a la relación entre estas ideas y la ideologia marxista de quien las propone. Por supuesto, no es necesario ser marxista para compartir los puntos de vista de Vygotski sobre el origen social del lenguaje o sobre las relaciones entre lenguaje e inteligencia. Tampoco es necesario ser marxista para creer - como yo creo- que el problema central de la psicología moderna consiste en conjugar las explicaciones fisiológicas con las explicaciones sociales del comportamiento humano entendido como una realidad única. Pero también me parece evidente que tanto en el caso de Vygotski como en el de Wallon fue su ideología marxista lo que les impulsó a reconocer con la misma fuerza los dos tipos de explicaciones y, sobre todo, les obligó a buscar en las sintesis de las dos, en la inserción de la sociedad histórica sobre la materia fisiológica la justificación de la conducta consciente e intencional. Recuérdese, por ejemplo, el conocido pasaje de Marx en el que compara el comportamiento del hombre al construir una casa con el de la abeja al construir las celdas del panal: el hombre es consciente de lo que hace y anticipa el resultado de su acción.

$Y$ resulta una ironia de la historia que Vygotski y Wallon, que trabajaban en los mismos años en el mismo campo y en la misma dirección, no llegasen a conocerse ni tuviesen ningún contacto. Pero es todavía más irónico, por no decir trágico, que la obra de los dos fuese descalificada, y en el caso de Vygotski sepultada en el silencio, cuando a mediados de los años treinta las altas instancias soviéticas decidieron que la única psicología compatible con el marxismo era la reflexologia. Cuando es evidente que la obra de Vygotski, con la de Wallon, han sido dos intentos serios, quizá los únicos intentos serios, de construir una teoria psicológica congruente con el marxismo mientras la reflexo- 
logia, cualquiera que sea su valor cientifico, no tiene nada de especificamente marxista.

Mi segunda observación se refiere a las raices intelectuales del pensamiento de Vygotski. En una época de ignorancia histórica generalizada en la que leer o citar un libro de psicología publicado hace diez años es ya una prueba de despiste, de no «estar al dia» conviene hacer un esfuerzo para recordar que Vygotski era un hombre, un jovencito mejor, de una cultura intelectual extraurdinaria y de una curiosidad ilimitada y que los años de su mayor actividad, tan corta por otra parte - la década de los veinte-, fueron años en Europa de auténtica ebullición en muchos campos y entre ellos el de la psicología que conoció entonces quizá el período más brillante de su historia. Todos sabemos que Vygotski conocía y discutió las primeras obras de Piaget. Pero también conocía a fondo y cita a menudo en sus obras a los psicólogos de la forma o gestalt como Koffka, los experimentos sobre formación de conceptos de Aasch, las teorias sobre el desarrollo infantil de Carlota Bühler, los estudios sobre lenguaje infantil de los esposos Stern, la filosofia del lenguaje de Carl Bühler, que ahora se está redescubriendo, la lingüistica estructural de Praga... Cualquiera de estos autores, si alguien se toma la pena de leerlos, resulta tan actual y tan incitante como Vygotski. Y para entender cabalmente a Vygotski haría falta, creo yo, tomarse la pena de leerlos.

Y una última observación. El interés que casi de golpe se ha despertado por el pensamiento de Vygotski y que parece que va a continuar creciendo en un futuro próximo no resulta difícil de explicar. Pasada la marea chomskiana, a la que antes he aludido, hemos descubierto o redescubierto la funcionalidad del lenguaje, hablar es en primer lugar comunicar y las formas y las variedades de la comunicación lingüistica y de su evolución son tan variadas que justifican todo tipo de investigaciones. Pero si no queremos vernos desbordados por una masa cada vez más enorme de datos empíricos inconexos necesitamos urgentemente una teoria psicolingüística de la génesis, el desarrollo y la naturaleza del lenguaje. Una teoría que parta de la función comunicativa y social que el lenguaje empieza por cumplir, pero que al mismo tiempo respete la especificidad del lenguaje y respete su peculiar relación con la inteligencia; especificidad y relación que Chomsky y Piaget, respectivamente, con tanta claridad pusieron de manifiesto. De lo que llevo dicho se desprende que la obra de Vygotski cumple satisfactoriamente estas condiciones. $Y$ es muy natural, por tanto, que numerosos psicolingüistas y psicólogos del lenguaje, especialmente los que se ocupan del lenguaje infantil, busquen en Vygotski la garantía del respeto a las caracteristicas propias del lenguaje que antes les ofrecían Piaget o Chomsky. Nada hay de malo en ello, sino todo lo contrario, e incluso es posible que así se esté iniciando una etapa brillante de la psicolingǘstica y del estudio del lenguaje infantil. A condición, claro está, de que no se olvide que Vygotski abrió, de forma genial, un camino y marcó una dirección llena de promesas, pero que no construyó una teoría articulada y coherente. Esto será la tarea de sus auténticos continuadores, o al menos el intentarlo. Porque si el redescubrimiento y el entusiasmo por Vygotski se reduce a la repetición ritual de sus formulaciones, su influencia no tendrá mayor alcance que el de una moda pasajera. 